\title{
Complications after posterior dislocation of the hip
}

Received: 14 November 2005 / Accepted: 15 November 2005 / Published online: 7 March 2006

C) Springer-Verlag 2006

\begin{abstract}
Thirty-five consecutive patients with unilateral posterior dislocation of the hip were studied for complications at an average follow-up of 4.6 years (range 2-10 years). Thompson-Epstein type IV dislocation was most frequent (10/35), reflecting an increase in high-speed motor vehicles in the developing countries. It is also a severe injury that leads to a maximum number of complications, which include avascular necrosis, osteoarthosis, sciatic nerve injury and heterotrophic ossification. Avascular necrosis and osteoarthritis of the hip were observed maximally in type IV patients, even when reduction was achieved in less than twelve hours and may reflect the severity of initial injury. Heterotrophic ossification was observed in five of the ten patients with type IV dislocation and was associated with multiple attempts at reduction. Sciatic nerve injury did not recover completely in all cases, especially when reduction was delayed over twelve hours. Observing that the greatest numbers of complications were seen among patients with type IV dislocations, it may be prudent to warn such individuals about the likely prognosis at the outset, especially in today's world when the demands and expectations are high.
\end{abstract}

Résumé 35 patients consécutifs présentant une luxation postérieure de la hanche ont été étudiés avec un recul moyen de 4,6 ans (2 à 10 ans). Les luxations de type 4 de Thompson-Epstein sont les plus fréquentes $(10 / 35)$ et sont le reflet de l'augmentation de la vitesse des véhicules à

\footnotetext{
A. J. Dwyer $(\bowtie) \cdot$ B. John · S. A. Singh · M. K. Mam

Department of Orthopaedic Surgery,

Christian Medical College \& Hospital,

Ludhiana, Punjab 141008, India

e-mail: amitabhdwyer@yahoo.com

Tel.: +44-1935-384287

Fax: +44-1935-384700

\section{A. J. Dwyer}

Department of Orthopaedic Surgery \& Trauma,

Yeovil District Hospital,

Higher Kingston,

Yeovil, Somerset, BA21 4AT, UK
}

moteur dans les pays développés. Il s'agit également de traumatismes sévères qui ont conduit la plupart du temps à des complications de nécroses avasculaires, de lésions dégénératives, de lésions du nerf sciatique et d'ossification hétérotopique. Ce sont les traumatismes sévères qui ont été à l'origine du maximum de complications. Les nécroses avasculaires et les arthroses de hanche sont surtout observées chez les patients de type IV, même si la réduction a été réalisée avant 12 heures. Les ossifications hétérotopique sont été observées chez 5 patients sur 10, notamment dans les luxations de type 4 , les lésions du nerf sciatique n'ont jamais récupéré complètement surtout lorsque la réduction a été retardée après 12 heures. Il faut remarquer que le plus grand nombre de complications ont été observées chez les patients dont la luxation était de type IV. Il est plus prudent dans ce cas là de faire part du pronostic réservé à ces patients, d'autant plus que la demande et l'attente d'un résultat parfait est très importante dans le monde d'aujourd'hui.

\section{Introduction}

Traumatic dislocation and fracture-dislocation of the hip is an absolute orthopaedic emergency that is steadily increasing in incidence. Early recognition and prompt, stable reduction is the essence of successful management. A delay in recognition and reduction leads to preventable complications and morbidity [9]. Prognostic factors include the time between injury and reduction, fracture-dislocation type, congruity of the acetabulum-femoral head articulation, adequacy and stability of the reduced hip joint [14] and severity of trauma [8].

Studies relating to specific problems in patients with posterior dislocation of the hip are mostly from the western literature $[2,3,5,9,11,14]$; however, this injury is becoming more frequent in the Indian sub-continent with the introduction of faster moving vehicles on the limited infrastructure of the developing world. We set out to study the various complications observed in long-term follow-up after treatment of posterior dislocation of the hip. 
Table 1 Type of dislocation, number of patients and complications

\begin{tabular}{lcclll}
\hline $\begin{array}{l}\text { Thompson- } \\
\begin{array}{l}\text { Epstein } \\
\text { types }\end{array}\end{array}$ & $\begin{array}{l}\text { of } \\
\text { patients }\end{array}$ & $\begin{array}{l}\text { Avascular } \\
\text { necrosis }\end{array}$ & $\begin{array}{l}\text { Osteoarthrosis } \\
\text { of the hip }\end{array}$ & $\begin{array}{l}\text { Sciatic Heterotro- } \\
\text { nerve } \\
\text { injury }\end{array}$ & $\begin{array}{l}\text { phic } \\
\text { ossification }\end{array}$ \\
\hline I & 9 & 0 & 0 & 0 & 0 \\
II & 4 & 1 & 2 & 0 & 0 \\
III & 7 & 2 & 1 & 1 & 0 \\
IV & 10 & 6 & 5 & 3 & 5 \\
V & 5 & 1 & 1 & 0 & 0 \\
Total & 35 & 10 & 9 & 4 & 5 \\
\hline
\end{tabular}

\section{Materials and methods}

Thirty-five consecutive patients with unilateral posterior dislocation of the hip that presented between 1990 and 2001 were followed up for an average of 4.6 years (range $2-10$ years). There were 30 men and five women with an average age of 39.5 years (range 10-70 years); half of them were aged 15-45 years. Nearly two-thirds of injuries $(23 / 35)$ involved the right extremity. All injuries occurred in road traffic accidents, with 31 of the 35 patients being four-wheeler occupants. Fourteen patients sustained ipsilateral lower limb injuries, while in eight the contralateral lower limb was involved. They were classified (Table 1) as per Thompson and Epstein [10] and type V dislocations were sub-classified according to Pipkin [7], with one each in subtypes I and III and three in subtype IV. Anterior, central, pathological and neglected dislocations of the hip were excluded. Following closed reduction all hips were mobilised on traction in bed within a week as comfort permitted. Type I patients, however, were mobilised earlier at three weeks post reduction with crutches starting from partial to full weight bearing, while the rest were mobilised by six weeks.

\section{Results}

Of the 35 patients treated with closed reduction, 28 were treated with the Allis method and six with the Bigelow method, while one irreducible hip in a patient warranted open reduction. However, one Pipkin [7] type III injury that presented with an undisplaced fracture required a hemiarthroplasty as the fracture displaced at attempted closed

Table 2 Interval between injury and time of reduction

\begin{tabular}{lllllll}
\hline Duration (h) & \multicolumn{6}{c}{ Number of patients by Thompson-Epstein type } \\
\cline { 2 - 7 } & Type I & Type II & Type III & Type IV & Type V & Total \\
\hline$\leq 6$ & 3 & 2 & 4 & 4 & 0 & 13 \\
7 to 12 & 5 & 1 & 1 & 2 & 5 & 14 \\
13 to 24 & 1 & 1 & 2 & 2 & 0 & 6 \\
$>24$ & 0 & 0 & 0 & 2 & 0 & 2 \\
Total & 9 & 4 & 7 & 10 & 5 & 35 \\
\hline
\end{tabular}

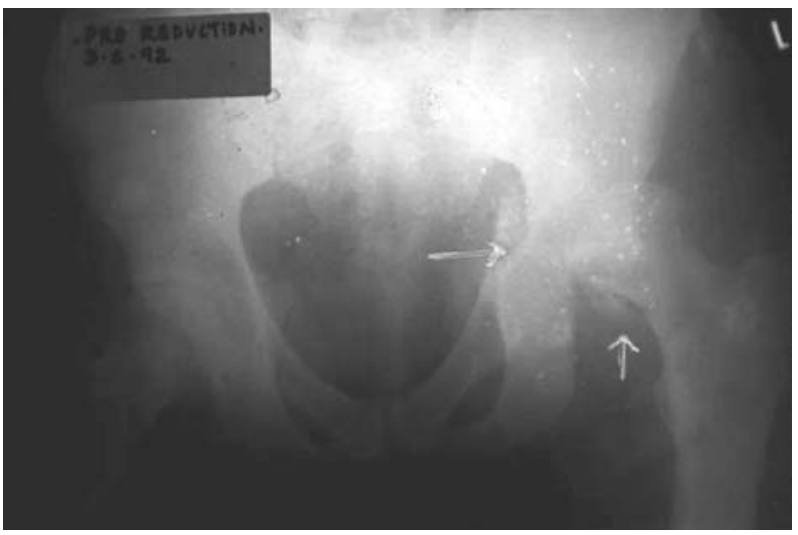

Fig. 1 X-ray of a 42-year-old man with Thompson-Epstein type IV dislocation of hip at presentation

reduction by the Allis method. Open reduction and internal fixation after initial closed reduction was performed in four patients with type III injury (comminution of the posterior acetabular rim). The hip was relocated within twelve hours in three quarters (27/35) of the patients (Table 2). Patients with type IV injury (Fig. 1) experienced the greatest number of complications at an average follow-up of 5.1 years (range 2-11 years) while no complications were observed among type I dislocations at an average follow-up of 6.2 years (range $2-11$ years). Heterotrophic ossification was observed in only half (5/10) of type IV dislocations. An increasing trend towards avascular necrosis was observed with increasing severity of dislocation, with most cases involving type IV injury (Table 1). Avascular necrosis was observed in three of the six patients with type IV injury (Fig. 2) even though the injuries were reduced in less than $12 \mathrm{~h}$. Of the hips closed reduced at first attempt, only $16 \%$ deteriorated to avascular necrosis, in contrast to $55.6 \%$ of those in which more than one attempt was made. Greater severity of trauma (types III and IV) resulted in

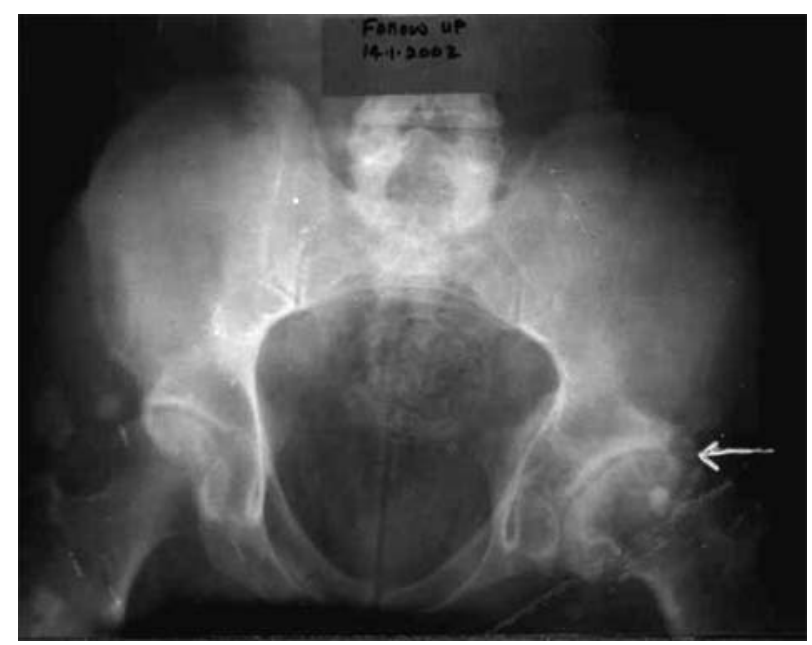

Fig. 2 Same patient as Fig. 1. X-ray of now 52-year-old man with Thompson-Epstein type IV dislocation of hip at 10-year follow-up: avascular necrosis of the femoral head 
sciatic nerve injury (Table 2), whereas there was no such injury among those in whom the trauma was less severe (types I and II). Sciatic nerve neuropraxia resolved in all the patients within three months of injury except for two with type IV injury where closed reduction was achieved twelve hours after injury. These two patients recovered partially within 14 months of treatment and required prolonged rehabilitation. Re-dislocation was observed in two hips with type IV injury and one with Pipkin [7] subtype IV injury. These two hips also developed osteoarthrosis and one deteriorated further with heterotrophic ossification and avascular necrosis that necessitated arthroplasty. Osteoarthrosis of the hip was observed among all groups in varying degrees except with type I injury. Two patients with type IV injury were unable to squat and sit cross-legged, a practice common on the Indian subcontinent, while two others with type II injury had partial restriction of these activities.

\section{Discussion}

The majority of our patients were men $(30 / 35)$ in fourwheeled vehicles $(31 / 35)$ in their most productive years of life (age group 30-45 years), similar to previous observations $[9,14]$. The right hip was predominantly involved, in contrast to earlier reports of more frequent left hip dislocation $[12,14]$, possibly because in most cases a right-sided oncoming vehicle crashed into the patient's vehicle. Also unlike previous reports $[11,14]$ type IV injuries were most common, reflecting the increasing severity of trauma among our patients in the developing world.

Avascular necrosis was most common (6/10) amongst type IV dislocations. Nearly half of the type III and IV patients (8/17) developed avascular necrosis, while only one of the 13 type I and II patients developed the condition. This observation is similar to the rates of avascular necrosis reported in the literature-less than $6 \%$ in type I and II dislocations and up to $50 \%$ among type III and IV dislocations [6] — and also endorses a rapidly reduced simple dislocation of the hip with no associated fracture that has few long-term complications [13]. The time that elapsed between injury and reduction also had an impact on the outcome following dislocation, with an increase in the rate of avascular necrosis of hip among patients with an interval of over six hours between injury and reduction (6/9). This is similar to the $4.8 \%$ rate of aseptic femoral head necrosis reported when reduction was achieved within six hours compared to $58.8 \%$ when reduction was achieved more than six hours post injury [5]. However, three patients developed avascular necrosis despite reduction being achieved in less than six hours.

We observed a frequent occurrence of heterotrophic ossification in relation to initial muscle damage and hematoma formation as observed by others [3], especially among type IV dislocations. Multiple attempts at reduction in three patients compounded the problem.
The cumulative average incidence of sciatic nerve injury reported in the literature is $10 \%$ [1]. We observed four $(11.4 \%)$ patients with sciatic nerve injury, of whom two recovered completely in less than three months while the other two had partial recovery at two-year follow-up. Partial neurological recovery in the latter two patients was associated with reduction being achieved more than twelve hours after injury and accords with an increase in the incidence after delayed reduction [4] and partial nerve recovery [1] as previously reported.

Post-traumatic osteoarthrosis of the hip was once again most frequent (5/10) among the type IV dislocations. However, the overall number of patients that developed post-traumatic osteoarthrosis of the hip (9/35) is comparable with earlier reports of up to $25 \%$ [2,6,9]. With regard to time to reduction, only one patient developed post-traumatic osteoarthrosis after achieving reduction in less than six hours, while there were four patients each with osteoarthrosis of hip following reduction between seven and twelve hours and over twelve hours after injury respectively.

Type IV dislocation of the hip is a serious injury that may lead to secondary osteoarthrosis of the hip even when reduction is carried out swiftly and adequately. Prompt reduction of the dislocation, though paramount, cannot always prevent complications, because avascular necrosis of the femoral head and post-traumatic osteoarthrosis of the hip may result from the initial injury and not necessarily from the delay in reduction [8]. Further soft tissue damage results following repeated attempts at closed reduction and may give rise to heterotrophic ossification and avascular necrosis. Sciatic nerve injury may not recover completely in all cases, especially if reduction is delayed over twelve hours, especially with severe (type IV) injury. Observing that patients with type IV suffered a maximum number of complications, it may be worthwhile warning the patient about the likely prognosis at the outset, especially in today's world when the demands and expectations are high.

\section{References}

1. Cornwall R, Radomisli TE (2000) Nerve injury in traumatic dislocation of the hip. Clin Orthop Relat Res 377:84-91

2. Dreinhofer KE, Schwarzkopf SR, Hass NP, Tscherne H (1994) Isolated traumatic dislocation of the hip. Long term results in 50 patients. J Bone Joint Surg [Br] 76:6-12

3. Epstein HC (1973) Traumatic dislocations of the hip. Clin Orthop Relat Res 92:116-142

4. Hillyard RF, Fox J (2003) Sciatic nerve injuries associated with traumatic posterior hip dislocations. Am J Emerg Med 21: 545-548

5. Hougaard K, Thomsen PB (1986) Traumatic posterior dislocation of the hip - prognostic factors influencing the incidence of avascular necrosis of the femoral head. Arch Orthop Trauma Surg 106:32-35

6. Hougaard K, Thomsen PB (1987) Coxarthrosis following traumatic posterior dislocation of the hip. J Bone Joint Surg [Am] 69:679-683

7. Pipkin G (1957) Treatment of grade IV fracture-dislocation of the hip. J Bone Joint Surg [Am] 39:1027-1042 
8. Rodriguez-Merchan EC, Goddard NJ (2000) Traumatic dislocation of the hip. Clin Orthop Relat Res 377:2-3

9. Sahin V, Karakas ES, Aksu S, Atlihan D, Turk CY, Halici M (2003) Traumatic dislocation and fracture dislocation of the hip: a long term follow-up study. J Trauma 53:520-529

10. Thompson VP, Epstein HC (1951) Traumatic dislocation of the hip: a survey of two hundred and four cases covering a period of twenty-one years. J Bone Joint Surg [Am] 33:746-778

11. Upadhyay SS, Moulton A (1981) The long term results of posterior dislocation of the hip. J Bone Joint Surg [Br] 63: $548-551$
12. Upadhyay SS, Moulton A, Burwell RG (1985) Biological factors predisposing to traumatic posterior dislocation of the hip. A selection process in the mechanism of injury. J Bone Joint Surg [Br] 67:232-236

13. Upadhyay SS, Moulton A, Srikrishnamurthy K (1983) An analysis of the late effects of traumatic posterior dislocation of the hip without fractures. J Bone Joint Surg [Br] 65:150-152

14. Yang RS, Tsuang YH, Hang YS, Liu TK (1991) Traumatic dislocation of the hip. Clin Orthop Relat Res 265:218-227 